\title{
Efficacy of extracorporeal membrane oxygenation for acute respiratory failure with interstitial lung disease; a case control nationwide dataset study in Japan
}

\section{Yuko Usagawa}

Oita University: Oita Daigaku https://orcid.org/0000-0001-5198-9662

Kosaku Komiya ( $\square$ komiyakh1@oita-u.ac.jp )

Oita University: Oita Daigaku

Mari Yamasue

Oita University: Oita Daigaku

Kiyohide Fushimi

Tokyo Medical and Dental University: Tokyo Ika Shika Daigaku

Kazufumi Hiramatsu

Oita University: Oita Daigaku

Jun-ichi Kadota

Oita University: Oita Daigaku

\section{Research}

Keywords: extracorporeal membrane oxygenation, interstitial lung disease, macrolides, mortality, respiratory failure

Posted Date: April 6th, 2021

DOI: https://doi.org/10.21203/rs.3.rs-152666/v2

License: (c) (i) This work is licensed under a Creative Commons Attribution 4.0 International License. Read Full License

Version of Record: A version of this preprint was published at Respiratory Research on July 24th, 2021. See the published version at https://doi.org/10.1186/s12931-021-01805-w. 


\section{Abstract}

Background: Since it is uncertain whether acute respiratory failure in patients with interstitial lung disease is reversible, indications for extracorporeal membrane oxygenation in these patients remain controversial, except for bridging to lung transplantation. The objective of this study was to clarify in-hospital mortality and prognostic factors in interstitial lung disease patients undergoing extracorporeal membrane oxygenation.

Methods: Case-control study. Using the Japanese Diagnosis Procedure Combination database from 2010 to 2017, we reviewed hospitalized interstitial lung disease patients receiving invasive mechanical ventilation and extracorporeal membrane oxygenation. As we focused on the efficacy of extracorporeal membrane oxygenation as an intervention for managing merely acute respiratory failure, patients treated with extracorporeal membrane oxygenation as a bridge to lung transplantation were excluded.

Results: A total of 164 interstitial lung disease patients receiving extracorporeal membrane oxygenation were included. In-hospital mortality of them was $74.4 \%$ (122/164). Compared with survivors, nonsurvivors were older and received high-dose cyclophosphamide, protease inhibitors, and antifungal drugs more frequently but macrolides and anti-influenza drugs less frequently. Multivariate analysis revealed the following factors were associated with in-hospital mortality: advanced age with an odds ratio (OR) of 1.048 and a $95 \%$ confidence interval $(\mathrm{Cl})$ of $1.015-1.082$, non-use of macrolides $(\mathrm{OR}, 0.264 ; 95 \% \mathrm{Cl}$, $0.118-0.589)$, and use of antifungal drugs (OR, 3.158; $95 \% \mathrm{Cl}, 1.377-7.242)$.

Conclusions: Approximately three quarters of interstitial lung disease patients undergoing extracorporeal membrane oxygenation died in hospital. Moreover, advanced age, non-use of macrolides, and use of antifungal drugs were found to correlate with a poor prognosis.

\section{Background}

Regardless of the type of interstitial lung disease (ILD), its associated acute respiratory failure (ARF) leads to a poor prognosis, especially in patients requiring invasive mechanical ventilation (IMV) [1-3]. Extracorporeal membrane oxygenation (ECMO), also known as extracorporeal life support, is a life-saving procedure established for severe respiratory failure, cardiac shock, and cardiac arrest. Veno-venous ECMO serves as an artificial lung that provides oxygenation and carbon dioxide removal by draining and reinfusing the blood through cannulas located in central veins. ECMO enables lung-protective ventilation and reduces complications such as ventilator-induced lung injury and oxygen toxicity [4]. Ever since ECMO therapy proved successful in influenza A (H1N1)-induced severe acute respiratory distress syndrome (ARDS) [5] as well as severe adult respiratory failure (CESAR trial) [6] in 2009, the use of ECMO for respiratory failure in adults has grown rapidly.

ECMO therapy is indicated in patients with potentially reversible causes of respiratory failure or those awaiting lung transplantation $[7,8]$. Due to difficulties in predicting the reversibility of respiratory failure, which arise from its heterogeneous causes, the indications for ECMO in ILD patients with ARF are a 
matter that should be discussed. Meanwhile, even in-hospital mortality and prognostic factors in ILD patients receiving ECMO have not been clarified. The aim of this study was to elucidate the mortality rate and prognostic factors in these patients by using nationwide data from the Japanese Diagnosis Procedure Combination (DPC) database.

\section{Methods}

\section{Study design and data source}

This was a retrospective case-control study using a nationwide inpatient database of acute care hospitals in Japan (i.e., the DPC database) to assess the efficacy of ECMO therapy for ARF in ILD patients treated between 2010 and 2017. The DPC is a case-mix classification system that is linked with a lump-sum payment system for inpatient care reimbursement. The Japanese DPC database includes data on the following characteristics: age, sex, body weight, admission and discharge status, main diagnosis, admission-precipitating diagnosis, resource-consuming diagnosis, comorbidities, complications, surgery, and procedures and medications administered during hospitalization. Diagnoses are recorded using International Classification of Diseases, 10 th revision, codes by attending physicians. Surgery and procedures performed during hospitalization are recorded according to the Japanese fee schedule for reimbursement.

In April 2020, this system included 1,757 hospitals with a total of 483,180 beds, which is thought to be enough to cover almost all acute inpatients in Japan [9]. The specificity and sensitivity of diagnoses and procedures recorded in the DPC database had already been validated by Yamana et al. [10]. Since all patient data were obtained in an anonymous manner, the requirement for individual informed consent was waived. This study was approved by the institutional review board of General Clinical Research Center, Oita University Hospital, on May 20, 2019 (approval no. 1613).

\section{Patient selection and data extraction}

Adult patients with both ILD codes (ICD-10: J670, J671, J672, J673, J674, J675, J676, J677, J678, J679, J700, J701, J702, J703, J704, J708, J82, J840, J841, J849, M0510, M313, M321, M330, M331, M332, M348, M351) and IMV codes were drawn from the 2010-2017 DPC database. After 388 cases with an ECMO code were found, ILD patients on ECMO for cardiac and temporary perioperative reasons were excluded so as to confine the study to those receiving ECMO for ARF. That is, patients with diagnostic or surgical codes pertaining to cardiovascular diseases such as coronary artery bypass grafting, intra-aortic balloon pumping, aortic dissection, cardiac arrest, and cardiogenic shock as well as those with codes related to lung cancer surgery, lung transplantation, and pulmonary alveolar proteinosis were excluded from this analysis (Fig. 1).

\section{Statistical analysis}

Statistical analyses were performed using IBM SPSS statistics software (version 22; IBM SPSS, Tokyo, Japan). Continuous variables were described as median \pm interquartile range (IQR), and categorical variables as frequency and percentage. The confidence interval in two-sided analyses was set at $95 \%$. 
The odds ratio of in-hospital mortality for each variable was estimated using a logistic regression model. Variables that were found to be significantly different $(p<0.05)$ between survivors and non-survivors on univariate analysis were entered into multivariate analysis in a stepwise manner. Statistical significance was defined as a p-value $<0.05$ for all analyses.

\section{Results}

This study enrolled 164 ILD patients undergoing ECMO for ARF in 88 hospitals, of whom 122 (74.4\%) died during hospitalization. The median age was 65 years (IQR, 57-71), with patients over 70 years old constituting $31 \%$ of the study population. Survivors were found to be significantly younger than nonsurvivors; however, no significant differences were observed in gender and body mass index (BMI) between the 2 groups (Table 1 ).

Table 1

Comparison of clinical characteristics between non-survivors group and survivors group.

\begin{tabular}{|c|c|c|c|c|}
\hline & $\begin{array}{l}\text { Non-survivors } \\
(n=122)\end{array}$ & $\begin{array}{l}\text { Survivors } \\
(n=42)\end{array}$ & Crude odds ratio & $\mathrm{p}$ value \\
\hline Female & $39(32.0)$ & $12(28.6)$ & $1.175(0.544-2.537)$ & 0.682 \\
\hline Age, year & $67(58-73)$ & $61(53-68)$ & $1.037(1.008-1.067)$ & 0.013 \\
\hline $20-29$ & $1(0.8)$ & $1(2.4)$ & $\mathrm{n} / \mathrm{a}$ & $\mathrm{n} / \mathrm{a}$ \\
\hline $30-39$ & $2(1.6)$ & $3(7.1)$ & & \\
\hline $40-49$ & $10(8.2)$ & $6(14.3)$ & & \\
\hline $50-59$ & $22(18.0)$ & $5(11.9)$ & & \\
\hline $60-69$ & $43(35.2)$ & $20(47.6)$ & & \\
\hline $70-79$ & $39(32.0)$ & $6(14.3)$ & & \\
\hline $80 \leq$ & $5(4.1)$ & $1(2.4)$ & & \\
\hline Age $\geq 65$ & $71(58.2)$ & $14(33.3)$ & $2.784(1.334-5.810)$ & 0.006 \\
\hline $\mathrm{BMI}, \mathrm{kg} / \mathrm{m}^{2}$ & $23.4(21.1-26.5)$ & $22.1(20.1-24.6)$ & $1.045(0.956-1.141)$ & 0.331 \\
\hline Ambulance transportation & $75(61.5)$ & $26(61.9)$ & $0.982(0.477-2.021)$ & 0.961 \\
\hline Hospital stay, day & $30(18-48)$ & $48(31-89)$ & $0.990(0.982-0.998)$ & 0.017 \\
\hline Diabetes & $29(23.7)$ & $9(21.4)$ & $1.143(0.490-2.666)$ & 0.756 \\
\hline Connective tissue disease & $32(26.2)$ & $7(16.7)$ & $1.778(0.718-4.400)$ & 0.213 \\
\hline
\end{tabular}


As shown in Table 2, most of the patients received broad-spectrum antibiotics, high-dose systemic steroids defined as the equivalent of methylprednisolone $\geq 500 \mathrm{mg} /$ day, and low-dose systemic steroids defined as the equivalent of methylprednisolone $<500 \mathrm{mg} /$ day. Survivors were treated more frequently with macrolides and anti-influenza drugs and less frequently with high-dose cyclophosphamide and protease inhibitors. ECMO duration was significantly longer in non-survivors than in survivors. KaplanMeier cumulative survival curve showed that successful weaning from ECMO occurred mostly during the early days after its initiation (Fig. 2). 
Table 2

Comparison of drugs and procedures between non-survivors and survivors.

\begin{tabular}{|c|c|c|c|c|}
\hline & $\begin{array}{l}\text { Non-survivors } \\
(n=122)\end{array}$ & $\begin{array}{l}\text { Survivors } \\
(n=42)\end{array}$ & Crude odds ratio & $\begin{array}{l}\mathrm{p} \\
\text { value }\end{array}$ \\
\hline Beta-lactam antibiotics & $65(53.3)$ & $21(50.0)$ & \multirow{3}{*}{$\begin{array}{l}1.140(0.565- \\
2.300) \\
0.968(0.480- \\
1.951)\end{array}$} & 0.714 \\
\hline Penicillin & $60(49.2)$ & $21(50.0)$ & & 0.927 \\
\hline Cephem & $99(81.1)$ & $30(71.4)$ & & 0.188 \\
\hline Carbapenem & & & $\begin{array}{l}1.722(0.767- \\
3.865)\end{array}$ & \\
\hline Macrolide & $41(33.6)$ & $25(59.5)$ & $\begin{array}{l}0.344(0.167- \\
0.708)\end{array}$ & 0.004 \\
\hline Fluoroquinolone & $68(55.7)$ & $21(50.0)$ & $\begin{array}{l}1.259(0.624- \\
2.542)\end{array}$ & 0.520 \\
\hline Tetracycline & $18(14.8)$ & $5(11.9)$ & $\begin{array}{l}1.281(0.444- \\
3.695)\end{array}$ & 0.647 \\
\hline Trimethoprim-sulfamethoxazole & $78(63.9)$ & $31(73.8)$ & $\begin{array}{l}0.629(0.288- \\
1.373)\end{array}$ & 0.245 \\
\hline Anti-MRSA drugs & $83(68.0)$ & $24(57.1)$ & $\begin{array}{l}1.596(0.777- \\
3.279)\end{array}$ & 0.203 \\
\hline Anti- influenza drugs & $10(8.2)$ & $9(21.4)$ & $\begin{array}{l}0.327(0.123- \\
0.873)\end{array}$ & 0.026 \\
\hline Anti-cytomegalovirus drugs & $29(23.8)$ & $8(19.0)$ & $\begin{array}{l}1.325(0.552- \\
3.182)\end{array}$ & 0.529 \\
\hline Anti-fungal drugs & $64(52.5)$ & $13(31.0)$ & $\begin{array}{l}2.462(1.169- \\
5.182)\end{array}$ & 0.018 \\
\hline Low-dose Steroid & $116(95.1)$ & $41(97.6)$ & $\begin{array}{l}0.472(0.055- \\
4.035)\end{array}$ & 0.493 \\
\hline High-dose Steroid & $105(86.1)$ & $33(78.6)$ & $\begin{array}{l}1.684(0.686- \\
4.133)\end{array}$ & 0.255 \\
\hline High-dose cyclophosphamide & $38(31.1)$ & $6(14.3)$ & $\begin{array}{l}2.714(1.055- \\
6.986)\end{array}$ & 0.038 \\
\hline Other immunosuppressant & $42(34.4)$ & $8(19.0)$ & $\begin{array}{l}2.231(0.948- \\
5.251)\end{array}$ & 0.066 \\
\hline Protease inhibitor & $66(54.1)$ & $14(33.3)$ & $\begin{array}{l}2.357(1.132- \\
4.910)\end{array}$ & 0.022 \\
\hline
\end{tabular}

Data are expressed as number of patients (\%).CHDF: Continuous hemodialysis filtration; ECMO: extracorporeal membrane oxygenation; MRSA: methicillin-resistant Staphylococcus aureus. 


\begin{tabular}{|lllll|}
\hline & $\begin{array}{l}\text { Non-survivors } \\
(\mathbf{n = 1 2 2})\end{array}$ & $\begin{array}{l}\text { Survivors } \\
\mathbf{( n = 4 2 )}\end{array}$ & Crude odds ratio & $\begin{array}{l}\mathbf{p} \\
\text { value }\end{array}$ \\
\hline $\begin{array}{l}\text { Recombinant human soluble } \\
\text { thrombomodulin }\end{array}$ & $43(35.2)$ & $12(28.6)$ & $\begin{array}{l}1.361(0.633- \\
2.926)\end{array}$ & 0.430 \\
\hline Sivelestat sodium & $64(52.5)$ & $18(42.9)$ & $\begin{array}{l}1.471(0.726- \\
2.983)\end{array}$ & 0.284 \\
\hline Duration of ECMO, day & $14(7.75-$ & $\begin{array}{l}7.5(4- \\
14.25)\end{array}$ & $\begin{array}{l}1.043(1.010- \\
1.077)\end{array}$ & 0.010 \\
\hline CHDF & $27.25)$ & $16(38.1)$ & $\begin{array}{l}2.985(1.446- \\
6.165)\end{array}$ & 0.003 \\
\hline $\begin{array}{l}\text { Data are expressed as number of patients (\%).CHDF: Continuous hemodialysis filtration; ECMO: } \\
\text { extracorporeal membrane oxygenation; MRSA: methicillin-resistant Staphylococcus aureus. }\end{array}$ & \\
\hline
\end{tabular}

Multivariate analysis, which involved constructing multiple models adjusted for statistically significant variables on univariate analysis in a stepwise manner, revealed that advanced age, non-use of macrolides, and use of antifungal drugs were significantly associated with in-hospital mortality (Table 3). Patients who were treated with macrolides were administered concurrently with other antibiotics in all except 1 case. To be more precise, azithromycin was prescribed to 57/66 patients (86.4\%); erythromycin, 7/66 (10.6\%); and clarithromycin, 6/66 (9.1\%), overlap permitted.

Table 3

Multivariate logistic regression analysis used to identify variables associated with in-hospital death.

\begin{tabular}{|lll|}
\hline & Adjusted odds ratio & p value \\
\hline Age, years & $1.048(1.015-1.082)$ & 0.004 \\
\hline Macrolides & $0.264(0.118-0.589)$ & 0.001 \\
\hline High-dose cyclophosphamide & $2.392(0.881-6.493)$ & 0.087 \\
\hline Antifungal drugs & $3.158(1.377-7.242)$ & 0.007 \\
\hline
\end{tabular}

\section{Discussion}

This study illustrated that in-hospital mortality of ILD patients receiving ECMO for ARF was approximately $75 \%$. It also demonstrated that advanced age, non-use of macrolides, and use of antifungal drugs were significantly associated with in-hospital mortality among these patients. 
A systematic review of ILD patients treated in intensive care units without ECMO showed that mortality was $65 \%$ in patients with idiopathic pulmonary fibrosis during the period $2005-2017$ and $48 \%$ in mixed ILD patients between 2010 and 2017 [2]. In our study, the rate of in-hospital mortality (74.4\%) in mixed ILD patients treated with ECMO turned out to be higher than previously reported mortality rates among patients receiving conventional treatments without ECMO. Possible reasons for the higher mortality in ECMO cases are that more severe patients who were refractory to conventional IMV were included, and that they might also have had complications associated with ECMO.

The decision regarding the time of ECMO weaning in successful cases or ECMO withdrawal in refractory cases needs to be discussed carefully. In this study, survivors were successfully weaned from ECMO after a median period of 8 days (IQR, 4-14) whereas ECMO was withdrawn in non-survivors at a median of 14 days (IQR, 8-27). Indeed, Kaplan-Meier survival curve indicated that successful weaning from ECMO was more frequent in the early days after its initiation. On the other hand, $67.2 \%$ of non-survivors died on the day of withdrawal, which implies that they relied entirely on ECMO as a life-sustaining procedure at the end of their lives. Our results suggest that continuation of ECMO over 14 days is less likely to produce any favorable outcome.

Here, we found that advanced age was significantly associated with high in-hospital mortality. The Respiratory EMO Survival Prediction score [11] and Predicting Death for Severe ARDS on Veno-venous ECMO (PRESERVE) score [12] have described young age as one of the favorable factors for receiving ECMO, regardless of the type of respiratory failure. Besides, the Extracorporeal Life Support Organization Guidelines for Adult Respiratory Failure published in 2017 have suggested considering a higher risk of a poor prognosis with increasing age [13]. Furthermore, the Extracorporeal Life Support Organization Coronavirus Disease 2019 Interim Guidelines have referred to age $\geq 65$ years as a relative contraindication for ECMO [14]. Our results in ILD patients are consistent with these guidelines. ECMO therapy consumes considerable medical resources, so the cost-benefit balance needs to be considered on a case-by-case basis, especially in elderly patients.

There was no significant difference in BMI between survivors and non-survivors, which is not in agreement with the PRESERVE scoring system stating that a BMI value $>30 \mathrm{~kg} / \mathrm{m}^{2}$ is related to a favorable prognosis [12]. This disparity in results could be attributed to the number of obese patients in our study $(n=9)$, which might have been too small to be meaningful for statistical analyses. Further research is needed to determine how obesity affects the prognosis of ILD patients undergoing ECMO.

In the present study, use of macrolides was found to significantly correlate with a favorable prognosis. It is known that macrolides have immunomodulatory effects [15-17] and their combinational administration is capable of diminishing mortality in critically ill patients with community-acquired pneumonia [18]. In fact, an official clinical practice guideline of the American Thoracic Society and Infectious Diseases Society of America has recommended macrolide-containing regimens for the treatment of hospitalized patients with severe pneumonia [19]. Besides, the effectiveness of azithromycin for treatment of acute exacerbation of idiopathic pulmonary fibrosis has been reported that mortality in 
patients treated with azithromycin was significantly lower than in those treated with fluoroquinolones [20]. Therefore, antibiotic therapy with macrolide-containing regimens might prove effective not only in patients with severe community-acquired pneumonia but also in ILD patients receiving ECMO.

Our study also demonstrated an association between using antifungal drugs and increased in-hospital mortality. Since observational studies are unable to determine causal relationships, it remains unclear whether antifungal drug use or fungal infections could have impacted the results. Antifungal drugs are generally administered when patients are thought to develop fungal infections during immunosuppressive therapy. Thus, a diagnosis of fungal infections, rather than antifungal drug use per se, might influence patients' prognosis.

In the current study, use of anti-influenza virus drugs was significantly associated with survival to discharge in the univariate analysis but lost its statistical significance in the multivariate analysis. The efficacy of ECMO in H1N1-related ARDS has been reported [5]. In this regard, while ECMO might be beneficial for influenza-related respiratory disorder itself, its efficacy could be limited when this disease is accompanied by ILD.

The strength of this study is that a large number of patients from a nationwide database were included to be analyzed. However, some limitations derived from the retrospective nature of the study. First, the subtype of ILD was uncertain because input of them was not required in DPC database. However, antifibrotic agents which were covered by Japanese health insurance only for patients with idiopathic pulmonary fibrosis in the study period were used in only 12 cases. Presumably, the number of idiopathic pulmonary fibrosis cases would be limited. Second, no standardized ECMO initiation and management protocol exists among hospitals, giving rise to selection and intervention bias. Finally, long-term outcomes could not be clarified owing to the lack of post-discharge information.

\section{Conclusions}

In conclusion, in-hospital mortality of ILD patients receiving ECMO for ARF would be nearly $75 \%$. The indications for ECMO in ILD patients who are not lung transplantation candidates should be carefully considered. Advanced age, non-use of macrolides, and use of anti-fungal drugs may be associated with a poor prognosis in ILD patients undergoing ECMO therapy.

\section{Abbreviations}

ARF: acute respiratory failure

BMl: body mass index

DPC: The Japanese Diagnosis Procedure Combination

ECMO: extracorporeal membrane oxygenation 
ILD: interstitial lung disease

IMV: invasive mechanical ventilation

IQR: interquartile range

\section{Declarations}

\section{Ethical approval}

The study protocol was approved by the institutional ethics committee of Oita University (approval no. 1613; approval date: May 20, 2019).

\section{Consent for participation and publication}

Since all patient data were obtained in an anonymous manner, the requirement for individual informed consent was waived.

\section{Availability of data and materials statement}

The datasets used and analyzed during the current study are available from the corresponding author on reasonable request.

\section{Competing interests}

All authors have stated that there are no competing interests in connection with this article.

\section{Funding information}

This research did not receive any specific grant from funding agencies in the public, commercial, or notfor-profit sectors.

\section{Authorship statement}

$\mathrm{YU}, \mathrm{KK}, \mathrm{KF}, \mathrm{KH}$, and JK designed this study and drafted the manuscript. YU, KK MY, and KF contributed to data collection, data analysis, and manuscript preparation.

\section{Acknowledgement}

Not applicable.

\section{References}

1. Gaudry S, Vincent F, Rabbat A, Nunes H, Crestani B, Naccache JM, Wolff M, Thabut G, Valeyre D, Cohen $\mathrm{Y}$, Mal $\mathrm{H}$ : Invasive mechanical ventilation in patients with fibrosing interstitial pneumonia. $J$ 
Thorac Cardiovasc Surg 2014, 147:47-53.

2. Huapaya JA, Wilfong EM, Harden CT, Brower RG, Danoff SK: Risk factors for mortality and mortality rates in interstitial lung disease patients in the intensive care unit. Eur Respir Rev 2018, 27.

3. Gannon WD, Lederer DJ, Biscotti M, Javaid A, Patel NM, Brodie D, Bacchetta M, Baldwin MR: Outcomes and Mortality Prediction Model of Critically III Adults With Acute Respiratory Failure and Interstitial Lung Disease. Chest 2018, 153:1387-1395.

4. Abrams D, Brodie D: Extracorporeal Membrane Oxygenation for Adult Respiratory Failure: 2017 Update. Chest 2017, 152:639-649.

5. Davies A, Jones D, Bailey M, Beca J, Bellomo R, Blackwell N, Forrest P, Gattas D, Granger E, Herkes R, et al: Extracorporeal Membrane Oxygenation for 2009 Influenza A(H1N1) Acute Respiratory Distress Syndrome. Jama 2009, 302:1888-1895.

6. Peek GJ, Mugford M, Tiruvoipati R, Wilson A, Allen E, Thalanany MM, Hibbert CL, Truesdale A, Clemens F, Cooper N, et al: Efficacy and economic assessment of conventional ventilatory support versus extracorporeal membrane oxygenation for severe adult respiratory failure (CESAR): a multicentre randomised controlled trial. Lancet 2009, 374:1351-1363.

7. Faverio P, De Giacomi F, Sardella L, Fiorentino G, Carone M, Salerno F, Ora J, Rogliani P, Pellegrino G, Sferrazza Papa GF, et al: Management of acute respiratory failure in interstitial lung diseases: overview and clinical insights. BMC Pulm Med 2018, 18:70.

8. Trudzinski FC, Kaestner F, Schäfers HJ, Fähndrich S, Seiler F, Böhmer P, Linn O, Kaiser R, Haake H, Langer F, et al: Outcome of Patients with Interstitial Lung Disease Treated with Extracorporeal Membrane Oxygenation for Acute Respiratory Failure. Am J Respir Crit Care Med 2016, 193:527-533.

9. Hayashida K, Murakami G, Matsuda S, Fushimi K: History and profile of Diagnosis Procedure Combination (DPC): development of real data collection system for acute inpatient care in Japan. $J$ Epidemiol 2020.

10. Yamana H, Moriwaki M, Horiguchi H, Kodan M, Fushimi K, Yasunaga H: Validity of diagnoses, procedures, and laboratory data in Japanese administrative data. J Epidemio/ 2017, 27:476-482.

11. Schmidt M, Bailey M, Sheldrake J, Hodgson C, Aubron C, Rycus PT, Scheinkestel C, Cooper DJ, Brodie $D$, Pellegrino V, et al: Predicting survival after extracorporeal membrane oxygenation for severe acute respiratory failure. The Respiratory Extracorporeal Membrane Oxygenation Survival Prediction (RESP) score. Am J Respir Crit Care Med 2014, 189:1374-1382.

12. Schmidt M, Zogheib E, Rozé H, Repesse X, Lebreton G, Luyt CE, Trouillet JL, Bréchot N, Nieszkowska $A$, Dupont $\mathrm{H}$, et al: The PRESERVE mortality risk score and analysis of long-term outcomes after extracorporeal membrane oxygenation for severe acute respiratory distress syndrome. Intensive Care Med 2013, 39:1704-1713.

13. Extracorporeal Life Support Organization (ELSO) Guidelines for Adult Respiratory Failure August, 2017 [www.elso.org]

14. Shekar K, Badulak J, Peek G, Boeken U, Dalton HJ, Arora L, Zakhary B, Ramanathan K, Starr J, Akkanti B, et al: Extracorporeal Life Support Organization Coronavirus Disease 2019 Interim 
Guidelines: A Consensus Document from an International Group of Interdisciplinary Extracorporeal Membrane Oxygenation Providers. Asaio j 2020, 66:707-721.

15. Zimmermann P, Ziesenitz VC, Curtis N, Ritz N: The Immunomodulatory Effects of Macrolides-A Systematic Review of the Underlying Mechanisms. Front Immunol 2018, 9:302.

16. Friedlander AL, Albert RK: Chronic macrolide therapy in inflammatory airways diseases. Chest 2010, 138:1202-1212.

17. Kanoh S, Rubin BK: Mechanisms of action and clinical application of macrolides as immunomodulatory medications. Clin Microbiol Rev 2010, 23:590-615.

18. Sligl WI, Asadi L, Eurich DT, Tjosvold L, Marrie TJ, Majumdar SR: Macrolides and mortality in critically ill patients with community-acquired pneumonia: a systematic review and meta-analysis. Crit Care Med 2014, 42:420-432.

19. Metlay JP, Waterer GW, Long AC, Anzueto A, Brozek J, Crothers K, Cooley LA, Dean NC, Fine MJ, Flanders SA, et al: Diagnosis and Treatment of Adults with Community-acquired Pneumonia. An Official Clinical Practice Guideline of the American Thoracic Society and Infectious Diseases Society of America. Am J Respir Crit Care Med 2019, 200:e45-e67.

20. Kawamura K, Ichikado K, Yasuda Y, Anan K, Suga M: Azithromycin for idiopathic acute exacerbation of idiopathic pulmonary fibrosis: a retrospective single-center study. BMC Pulm Med 2017, 17:94.

\section{Tables}

Table 1 Comparison of clinical characteristics between non-survivors group and survivors group.

\begin{tabular}{|l|l|l|l|l|}
\hline & $\begin{array}{l}\text { Non-survivors } \\
(\mathrm{n}=122)\end{array}$ & $\begin{array}{l}\text { Survivors } \\
(\mathrm{n}=42)\end{array}$ & Crude odds ratio & $\mathrm{p}$ value \\
\hline Female & $39(32.0)$ & $12(28.6)$ & $1.175(0.544-2.537)$ & 0.682 \\
\hline Age, year & $67(58-73)$ & $61(53-68)$ & $1.037(1.008-1.067)$ & 0.013 \\
\hline $\begin{array}{l}20-29 \\
30-39\end{array}$ & $1(0.8)$ & $1(2.4)$ & $\mathrm{n} / \mathrm{a}$ & $\mathrm{n} / \mathrm{a}$ \\
$40-49$ & $2(1.6)$ & $3(7.1)$ & & \\
$50-59$ & $10(8.2)$ & $6(14.3)$ & & \\
$60-69$ & $22(18.0)$ & $5(11.9)$ & & \\
$70-79$ & $43(35.2)$ & $6(147.6)$ & & \\
$80 \leq$ & $39(32.0)$ & $1(2.4)$ & & \\
& $5(4.1)$ & & & \\
& & & & \\
& & & & \\
& & $14(33.3)$ & $2.784(1.334-5.810)$ & 0.006 \\
\hline Age $\geq 65$ & $71(58.2)$ & $22.1(20.1-24.6)$ & $1.045(0.956-1.141)$ & 0.331 \\
\hline BMI, kg/m & $23.4(21.1-26.5)$ & $26(61.9)$ & $0.982(0.477-2.021)$ & 0.961 \\
\hline Ambulance transportation & $75(61.5)$ & $48(31-89)$ & $0.990(0.982-0.998)$ & 0.017 \\
\hline Hospital stay, day & $30(18-48)$ & $9(21.4)$ & $1.143(0.490-2.666)$ & 0.756 \\
\hline Diabetes & $29(23.7)$ & $7(16.7)$ & $1.778(0.718-4.400)$ & 0.213 \\
\hline Connective tissue disease & $32(26.2)$ & & & \\
\hline
\end{tabular}

Data are expressed as number of patients (\%) and median (IQR). BMI: body mass index; IQR: interquartile range; n/a: not assessed. 
Table 2 Comparison of drugs and procedures between non-survivors and survivors.

\begin{tabular}{|c|c|c|c|c|}
\hline & $\begin{array}{l}\text { Non- } \\
\text { survivors } \\
(\mathrm{n}=122)\end{array}$ & $\begin{array}{l}\text { Survivors } \\
(\mathrm{n}=42)\end{array}$ & Crude odds ratio & $\begin{array}{l}\mathrm{p} \\
\text { value }\end{array}$ \\
\hline \multicolumn{5}{|l|}{ Beta-lactam antibiotics } \\
\hline Penicillin & $\begin{array}{l}65(53.3) \\
60(49.2)\end{array}$ & $\begin{array}{l}21(50.0) \\
21(50.0)\end{array}$ & $\begin{array}{l}1.140(0.565- \\
2.300)\end{array}$ & $\begin{array}{l}0.714 \\
0.927 \\
0.90\end{array}$ \\
\hline Carbapenem & $99(81.1)$ & & $\begin{array}{l}0.968(0.480- \\
1.951) \\
1.722(0.767- \\
3.865)\end{array}$ & \\
\hline Macrolide & $41(33.6)$ & $25(59.5)$ & $0.344(0.167-$ & 0.004 \\
\hline Fluoroquinolone & $68(55.7)$ & $21(50.0)$ & $1.259(0.624-$ & 0.520 \\
\hline Tetracycline & $18(14.8)$ & $5(11.9)$ & $1.281(0.444-$ & 0.647 \\
\hline Trimethoprim-sulfamethoxazole & $78(63.9)$ & $31(73.8)$ & $0.629(0.288-$ & 0.245 \\
\hline Anti-MRSA drugs & $83(68.0)$ & $24(57.1)$ & $1.596(0.777-$ & 0.203 \\
\hline Anti- influenza drugs & $10(8.2)$ & $9(21.4)$ & $0.327(0.123-$ & 0.026 \\
\hline Anti-cytomegalovirus drugs & $29(23.8)$ & $8(19.0)$ & $\begin{array}{l}1.325(0.552- \\
3.182)\end{array}$ & 0.529 \\
\hline Anti-fungal drugs & $64(52.5)$ & $13(31.0)$ & $2.462(1.169-$ & 0.018 \\
\hline Low-dose Steroid & $116(95.1)$ & $41(97.6)$ & $0.472(0.055-$ & 0.493 \\
\hline High-dose Steroid & $105(86.1)$ & $33(78.6)$ & $1.684(0.686-$ & 0.255 \\
\hline High-dose cyclophosphamide & $38(31.1)$ & $6(14.3)$ & $2.714(1.055-$ & 0.038 \\
\hline Other immunosuppressant & $42(34.4)$ & $8(19.0)$ & $2.231(0.948-$ & 0.066 \\
\hline Protease inhibitor & $66(54.1)$ & $14(33.3)$ & $2.357(1.132-$ & 0.022 \\
\hline $\begin{array}{l}\text { Recombinant human soluble } \\
\text { thrombomodulin }\end{array}$ & $43(35.2)$ & $12(28.6)$ & $\begin{array}{l}1.361(0.633- \\
2.926)\end{array}$ & 0.430 \\
\hline Sivelestat sodium & $64(52.5)$ & $18(42.9)$ & $1.471(0.726-$ & 0.284 \\
\hline Duration of ECMO, day & $\begin{array}{l}14(7.75- \\
27.25)\end{array}$ & $\begin{array}{l}7.5(4- \\
14.25)\end{array}$ & $\begin{array}{l}1.043(1.010- \\
1.077)\end{array}$ & 0.010 \\
\hline CHDF & $79(64.8)$ & $16(38.1)$ & $\begin{array}{l}2.985(1.446- \\
6.165)\end{array}$ & 0.003 \\
\hline
\end{tabular}

Data are expressed as number of patients (\%).CHDF: Continuous hemodialysis filtration; ECMO: extracorporeal membrane oxygenation; MRSA: methicillin-resistant Staphylococcus aureus.

Table 3 Multivariate logistic regression analysis used to identify variables associated with inhospital death.

\begin{tabular}{|l|l|l|}
\hline & Adjusted odds ratio & $\mathrm{p}$ value \\
\hline Age, years & $1.048(1.015-1.082)$ & 0.004 \\
\hline Macrolides & $0.264(0.118-0.589)$ & 0.001 \\
\hline High-dose cyclophosphamide & $2.392(0.881-6.493)$ & 0.087 \\
\hline Antifungal drugs & $3.158(1.377-7.242)$ & 0.007 \\
\hline
\end{tabular}




\section{Figures}

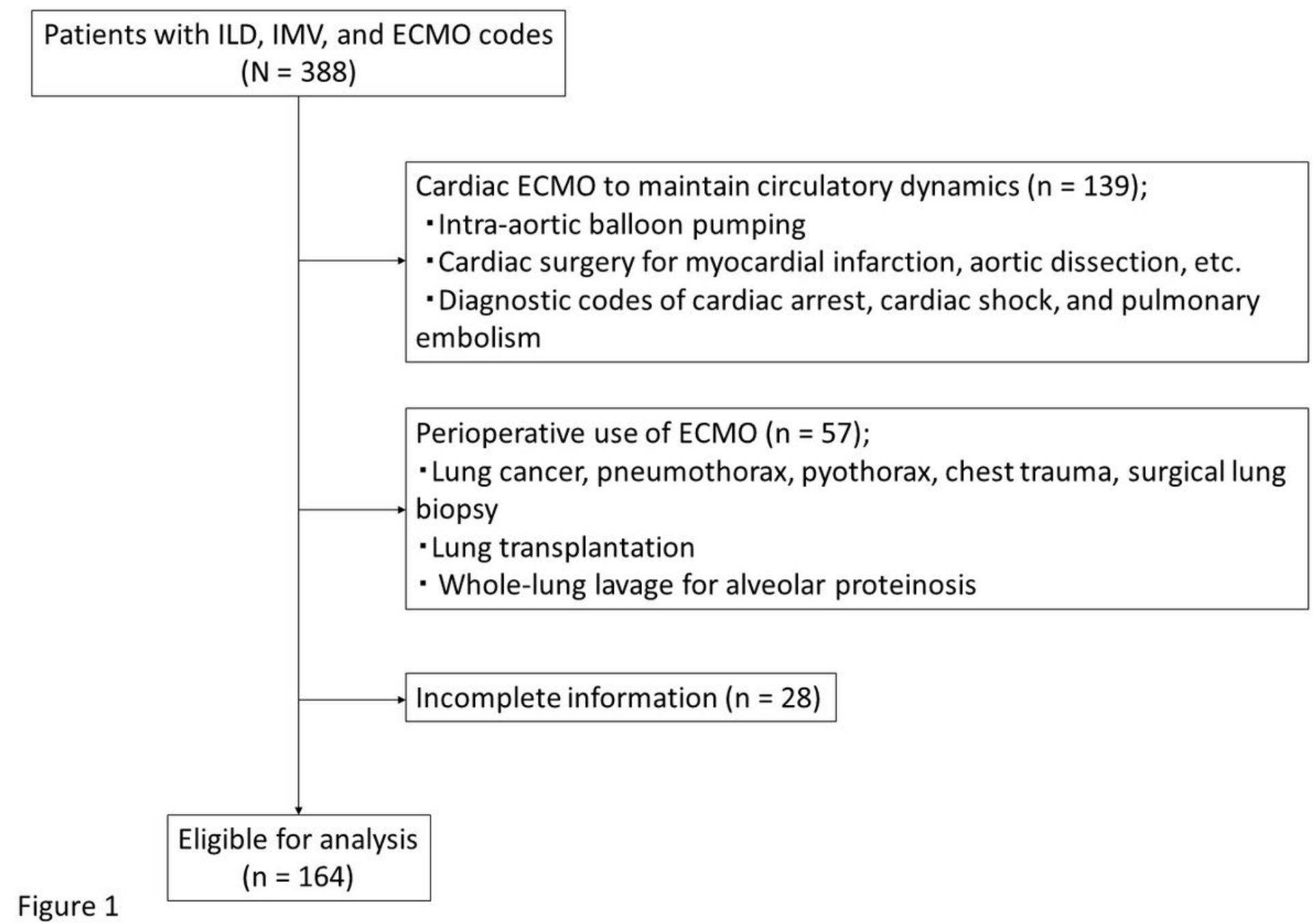

Figure 1

Patient selection diagram. 


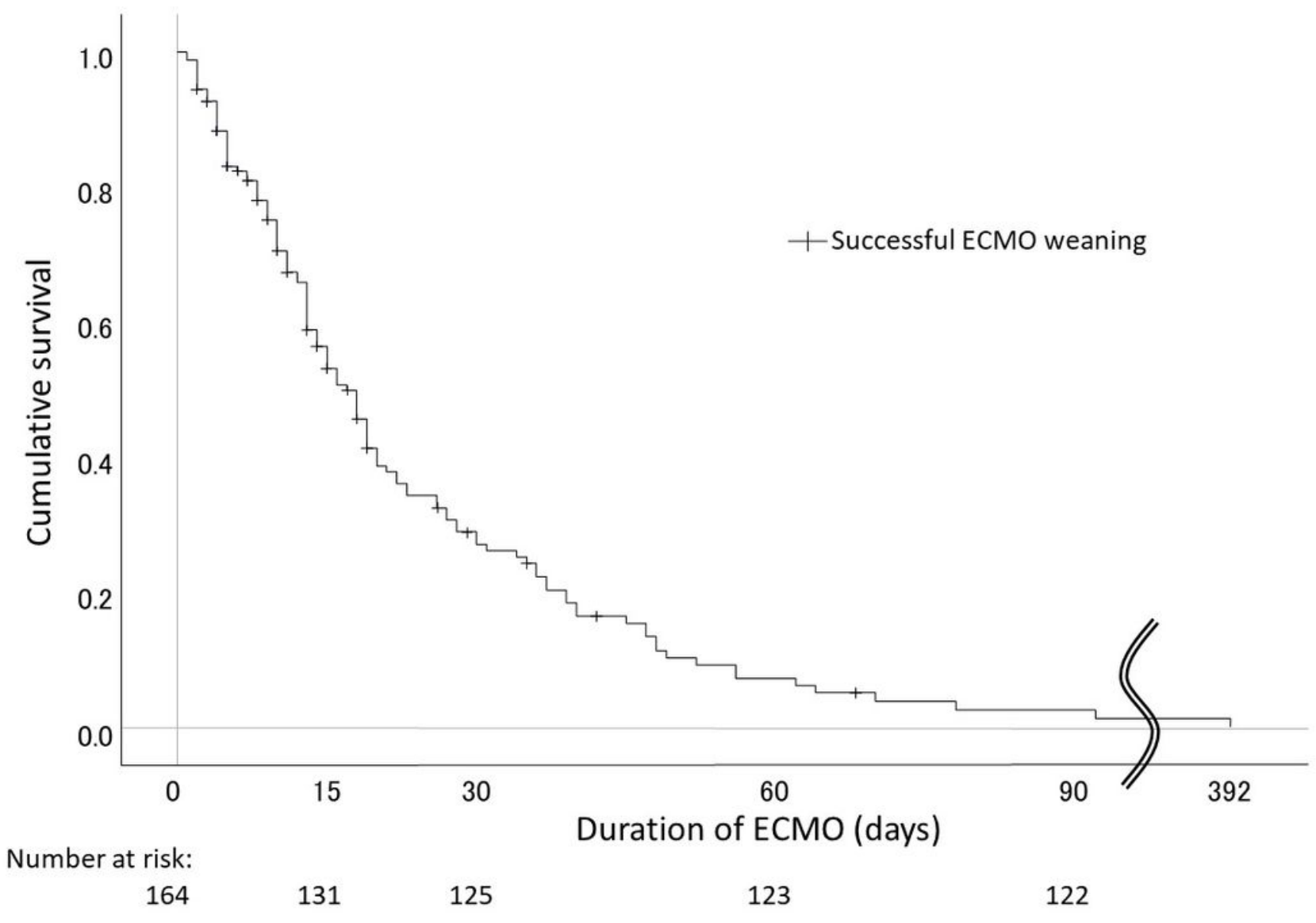

Figure 2

Figure 2

Kaplan-Meier curve plotted for cumulative survival in relation to the duration of extracorporeal membrane oxygenation for acute respiratory failure among interstitial lung disease patients. 